\title{
MTRA-Schülerprogramm auf dem Röntgenkongress
}

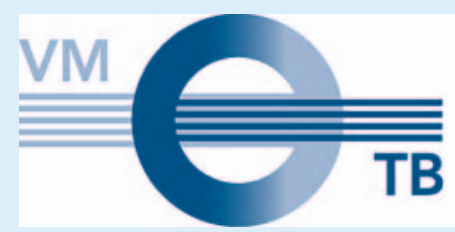

\section{VEREINIGUNG MEDIZINISCH-TECHNISCHER BERUFE}

in der Deutschen Röntgengesellschaft e.V.

Auch im Jahr 2020 möchte die Vereinigung Medizinisch-Technischer Berufe in der DRG (VMTB) allen MTRA-Schülerinnen und -Schülern die Möglichkeit bieten, am MTRA-Schülerprogramm des Deutschen Röntgenkongresses teilzunehmen.

Ein spezielles und abwechslungsreiches Programm für MTRA in Ausbildung wird erneut an 2 Tagen angeboten: am Mittwoch, 20. Mai 2020 von 12:30-18:30 Uhr, und am Donnerstag, 23. Mai 2020 von 11:00-14:00 Uhr. Sowohl am Mittwoch als auch am Donnerstag besteht zudem die Möglichkeit, an anderen Vorträgen des Röntgenkongresses teilzunehmen oder über die Industrieausstellung zu gehen.

Spannend wird es dann zusätzlich am Ende des Schülerprogramms, wenn der VMTB-
Schülerpreis für die 3 besten Vorträge verliehen wird. Aber auch zum MTRA-Vortragsprogramm und zur Industrieausstellung sind die MTRA-Schülerinnen und -Schüler vom 20.-23.05.2020 in Leipzig herzlich willkommen. Das Programm und noch viel mehr finden Sie unter www.roent genkongress.de.

Die Anmeldung der Schülerinnen und Schüler erfolgt über die Kongresshomepage (www.roentgenkongress.de > Anmeldung). Bitte melden Sie nur die Schülerinnen und Schüler an, die ihre Teilnahme verbindlich zugesichert haben. Stornierungen sind kostenpflichtig. Während der Registrierung ist es notwendig, dass die Schülerinnen und Schüler ein Foto oder einen Scan des Schulausweises hochladen. Es ist ebenfalls mög- lich, dass sich Schülerinnen und Schüler einzeln anmelden.

Weitere Informationen zur Anreise, ÖPNVTicket und Unterkunft finden Sie auf www. vmtb.de > Veranstaltungen > Verlinkung zum „Schülerprogramm“ sowie auf www. roentgenkongress.de.

Für Fragen zur Anmeldung von MTRA-Schülern steht Ihnen Dr. Erik Gührs gerne zur Verfügung (Telefon-Nr. (030) 916 070-15, guehrs@drg.de). Wir würden uns freuen, wenn wir mit Ihnen gemeinsam einen erfolgreichen Röntgenkongress erleben dürften und wünschen Ihnen bereits heute eine gute Anreise.

Ihre VMTB 